\title{
SABERES DOS SUPERVISORES NO CONTEXTO DO PIBID: FORMAÇÃO E PARCERIA
}

\author{
KNOWLEDGE OF THE SUPERVISORS IN PIBID: \\ TRAINING AND PARTNERSHIP
}

\section{SABERES DE LOS SUPERVISORES EN EL CONTEXTO DEL PIBID: FORMACIÓN Y PARECERÍA}

\author{
Laura Noemi Chaluh ${ }^{\mathrm{I}}$ \\ BÉTSAMAR SCOPINHO MARTINS ${ }^{\text {II }}$ \\ Maria Antonia Ramos de Azevedo ${ }^{\text {III }}$ \\ ANDREIa Osti ${ }^{\mathrm{IV}}$
}

Resumo Neste artigo, discutimos o lugar do professor supervisor no contexto do Pibid (Programa Institucional de Início à Docência). Ele é responsável por acompanhar e supervisionar as atividades dos bolsistas de iniciação à docência no ambiente escolar. Problematizamos quais os saberes necessários para o professor supervisor a partir de: a) escritas elaboradas pela professora supervisora e pelos bolsistas e registradas no caderno coletivo, b) relatos individuais dos bolsistas e que dizem da contribuição do professor supervisor no processo de formação docente. Acreditamos que a formação inicial dos bolsistas no contexto escolar é favorecida pelas práticas formativas do supervisor do Pibid.

Palavras-chave: Pibid; supervisor; saberes; escola-universidade.

Abstract We discuss, in this paper, the place of the supervising teacher in Pibid - Programa Institucional de Início à Docência (Institutional Program of Initiation to Teaching). It is responsible for monitoring and supervising the activities of the initiation to teaching scholars at school. We problematize what knowledge the supervisor teacher needs from:

Universidade Estadual Paulista (UNESP), Rio Claro/SP - Brasil.

II Rede Municipal de Educação/Rio Claro/SP - Brasil.

III Universidade Estadual Paulista (UNESP), Rio Claro/SP - Brasil.

IV Universidade Estadual Paulista (UNESP), Rio Claro/SP - Brasil. 
written recorded in the collective book by the supervisor teacher and the scholars, b) individual reports of scholars that deal with the contribution of the supervising teacher in the process of teacher training. We believe that the initial training of the scholars in school is favored by the educational practices of Pibid supervisor.

KeY-wORds: PIBID; SUPERVISOR; KNOWLEDGE; SCHOOL-UNIVERSITY.

Resumen En este artículo socializamos una parte de la experiencia vivida en el ámbito de un sub proyecto Pibid (Programa Institucional de Beca de Iniciación a la Docencia) en el contexto de una escuela municipal de enseñanza primaria de una ciudad del interior del estado de San Pablo. Problematizamos el lugar del profesor supervisor en el contexto del Pibid que es responsable por acompañar e supervisar las actividades de los becarios de iniciación a la docencia en el ambiente escolar. Discutimos cuáles son los saberes necesarios para la actuación del profesor supervisor. Para esto, socializamos escritas elaboradas por la profesora supervisores e por los becarios y que quedaron registrados en el cuaderno colectivo; también tracemos relatos individuales de los becarios que legitiman el papel del profesor supervisor como formador. El trabajo deja en evidencia que la formación inicial de los becarios en el contexto escolar es favorecido por las prácticas de formación del profesor supervisor del Pibid; Con esto, el Pibid, además de contribuir efectivamente en la constitución docente de los futuros profesores, afianza la parecería de la escuela con la universidad, una parecería que legitima la colaboración entre las dos instancias consideradas como legítimos espacios formativos.

Palavras Clave: Formación inicial; escuela; universidad; SABeres del docente

\section{INTRODUÇÃo}

Neste trabalho, socializamos parte da experiência vivida no contexto do subprojeto Pibid "Escola e universidade pensando a formação docente interdisciplinar: investigação, reflexão e ação", financiado pela Capes (Coordenação de Aperfeiçoamento de Pessoal de Nível Superior), e que foi desenvolvido no período de março de 2011 a dezembro de 2013. O referido subprojeto tinha a intencionalidade de que os bolsistas pudessem investigar e refletir a respeito do contexto escolar tanto nos aspectos pedagógicos como nos da gestão escolar, já que isso possibilitaria uma compreensão ampla da formação para a docência.

Esse subprojeto foi pensado e construído por um grupo de professores do Departamento de Educação de uma universidade pública do interior do Estado de São Paulo. O grupo estava constituído por duas professoras da área de Didática, dois professores da área de Geografia, uma professora da área de Psicologia, um professor da área de Sociologia, e dois professores da área de Educação Física. O interesse comum era desenvolver ações conjuntas, apoiadas numa visão interdisciplinar da formação para a docência. Em princípio, a promoção da interdisciplinaridade já estaria garantida pela pluralidade de áreas que estariam discutindo um mesmo objeto de estudo, a escola. 
O projeto foi aprovado e a inserção dos alunos nas escolas aconteceu em julho de 2011. No início, o projeto foi desenvolvido em três escolas de Ensino Fundamental II da rede estadual paulista, e contávamos com 15 bolsistas ID (Iniciação à Docência).

No ano de 2012, com novo edital, houve a possibilidade de aumentar o número de bolsistas no projeto original e ampliar o número de escolas. Foi assim que o grupo de professores decidiu pela inclusão de uma escola de Ensino Fundamental I e de mais 15 bolsistas para integrar o subprojeto. Com essas inclusões, também outras duas professoras da universidade se vincularam ao subprojeto inicial e mais uma professora supervisora.

O projeto (2011-2013) contou com 30 bolsistas, quatro professores supervisores, nove professores colaboradores e uma professora responsável pela coordenação geral do projeto.

Este trabalho traz discussões a partir do trabalho desenvolvido na escola municipal de Ensino Fundamental I, que foi incluída no subprojeto Pibid em agosto de 2012. Foi nessa escola que seis ${ }^{1}$ bolsistas iniciaram suas atividades: quatro alunas da Licenciatura Plena em Pedagogia, uma aluna do curso de Geografia, e um aluno da Licenciatura em Educação Física.

Três das autoras deste trabalho foram orientadoras dos bolsistas de Iniciação à Docência e a outra autora foi a professora supervisora desses alunos na escola.

Este trabalho tem a intencionalidade de legitimar o fazer da professora supervisora Pibid como formadora de futuros professores. Considerando a importância do fazer do supervisor, é que problematizamos quais os saberes necessários para poder assumir esse lugar privilegiado e que tem como uma das tarefas possibilitar a articulação da organização do trabalho pedagógico nas parcerias estabelecidas entre cada professor com seus bolsistas; entre os bolsistas com a equipe de gestão e com os funcionários. Para poder discutir essas questões, trazem7os a experiência da professora supervisora desse grupo de bolsistas a partir de registros elaborados nesse período e que nos permitem problematizar a temática em questão.

\section{PIBID: PROGRAMA DE FORMAÇÃO DE FUTUROS PROFESSORES}

O Programa de Iniciação à Docência (Pibid), proposto pelo MEC/Capes (Coordenação de Aperfeiçoamento de Pessoal de Nível Superior) ${ }^{2}$ em 2007, teve a intenção de fomentar a iniciação à docência objetivando melhor qualificá-la, a partir de propostas de atividades construídas em parceria com a escola. O Programa promove a inserção dos estudantes no ambiente das escolas públicas desde o início da sua formação acadêmica para desenvolverem atividades didático-pedagógicas sob orientação de um docente da licenciatura e de um professor da escola.

Para Gatti, André, Gimenes e Ferragut (2014, p. 10), um dos diferenciais desse programa está atrelado à concessão de bolsas tanto para os estudantes das licenciaturas, como para os professores das universidades que os orientam e para professores de escolas públicas (chamados de supervisores). Os professores supervisores são aqueles

\footnotetext{
Em determinado momento, o grupo ficou constituído por cinco bolsistas.

2 Site da Capes: http://www.capes.gov.br/
} 
"que acompanham as atividades dos bolsistas no espaço escolar, atuando assim como coformadores no processo de iniciação à docência, em articulação com o formador da universidade".

São objetivos do programa: incentivar a formação de docentes em nível superior para a educação básica; contribuir para a valorização do magistério; elevar a qualidade da formação inicial de professores nos cursos de licenciatura, promovendo a integração entre educação superior e educação básica; inserir os licenciandos no cotidiano de escolas da rede pública de educação, proporcionando-lhes oportunidades de criação e participação em experiências metodológicas, tecnológicas e práticas docentes de caráter inovador e interdisciplinar que busquem a superação de problemas identificados no processo de ensino-aprendizagem; incentivar escolas públicas de educação básica, mobilizando seus professores como coformadores dos futuros docentes e tornando as escolas protagonistas nos processos de formação inicial para o magistério; e contribuir para a articulação entre teoria e prática necessárias à formação dos docentes, elevando a qualidade das ações acadêmicas nos cursos de licenciatura.

Considerando que a melhoria da qualidade de ensino se faz necessária pautada na articulação entre as diferentes áreas de conhecimento, o subprojeto "Escola e universidade pensando a formação docente interdisciplinar: investigação, reflexão e ação", desenvolvido na UNESP (Campus de Rio Claro), buscou a interdisciplinaridade e a articulação das diferentes disciplinas, implementando uma prática de verticalidade e horizontalidade da Matriz Curricular, em que as interfaces das disciplinas e suas possíveis inter-relações fossem integradas ao conhecimento escolar.

A execução desse projeto interdisciplinar possibilitou uma estreita articulação entre teoria e prática, uma vez que supervisores, bolsistas e professores conseguiram construir conjuntamente um campo de interlocução, discussão e reflexão sobre as práticas desenvolvidas. Cabe esclarecer que as necessidades da escola e dos professores em relação aos conteúdos que precisavam ser articulados foram priorizadas. Isso direcionou nosso olhar para a organização de um trabalho dialógico em que fosse possível criar uma metodologia e uma organização de ensino voltada para a necessidade identificada pelos docentes e para o aperfeiçoamento dos alunos bolsistas em formação.

Dos encontros e discussões mantidos com os bolsistas, das escritas produzidas por eles, consideramos que a experiência do Pibid lhes possibilitou conhecer de maneira mais próxima as contradições, desafios e problemas enfrentados pelos docentes em exercício. Entre as atividades, realizaram observações e registros no caderno de campo de todas as situações observadas e vivenciadas na escola (aulas, atividades culturais, visitas, trabalhos de campo, reuniões de pais, reuniões pedagógicas em Horário de Trabalho Pedagógico Coletivo, reuniões de planejamento, de conselhos de classe, entre outras) que permitiram refletir, repensar e direcionar as intervenções junto aos alunos. $\mathrm{O}$ exame de documentos da escola (Projeto Político Pedagógico, Planos de Trabalho, entre outros), assim como a realização de entrevistas com professoras/es, também contribuíram para uma aproximação entre bolsistas e docentes. 
Essa aproximação entre a prática do professor com a formação inicial dos licenciandos oportunizou aos bolsistas o pensar sobre a transposição dos saberes científicos em saberes escolares. Por sua vez, a convivência de professores e alunos da rede com os espaços acadêmicos onde se produz o conhecimento científico, segundo Fazenda (2002), amplia o diálogo com outras formas de conhecimento, permitindo o enriquecimento da nossa relação com o outro e com o mundo.

Retomando os objetivos da Capes e analisando sua inserção no projeto que desenvolvemos, podemos afirmar que os bolsistas efetivamente articularam a teoria tratada na universidade com a prática e a teoria que sustentam as ações na sala de aula, elevando assim a qualidade do planejamento das suas ações. Também tornaram-se protagonistas do próprio planejamento, uma vez que precisavam elaborar planos de aula, apresentar aos professores e executar tais atividades. A oportunidade de pesquisar, estudar e preparar atividades específicas, discutida com o professor da escola, possibilitou uma experiência prévia da turma de alunos e assegurou ao bolsista ter orientação adequada para intervir, a partir dos conselhos de um profissional que realmente passou por essas experiências, o que promoveu a integração entre a educação superior e a educação básica.

Compreendendo a interdisciplinaridade como uma forma de trabalhar um tema com abordagem em diferentes disciplinas, ultrapassando o pensamento fragmentado, o fazer pedagógico, numa perspectiva interdisciplinar, "não dilui as disciplinas, ao contrário, mantém sua individualidade. Integra as disciplinas a partir da compreensão das múltiplas causas ou fatores que intervêm sobre a realidade" (BRASIL, 1999, p. 89).

Em consonância com os objetivos da Capes, nosso subprojeto não apenas reconheceu a escola como um espaço de produção e apropriação de conhecimento, tornando-a partícipe do projeto desenvolvido, como promoveu a renovação do processo de ensino e aprendizagem ao propor atividades diversificadas direcionadas às necessidades expressas pelos docentes. Valorizou a proposta pedagógica da escola, reconhecendo as especificidades de seu currículo e direcionando ações que contribuíssem para a elevação da qualidade do ensino.

Nosso projeto partiu do pressuposto de que a perspectiva epistemológica da interdisciplinaridade não pressupõe unicamente a integração, mas a interação das disciplinas, de seus conceitos e diretrizes, de sua metodologia, de seus procedimentos, suas informações na organização do ensino, enfim, traz a ideia da não globalização dos conteúdos simplesmente, mas, sobretudo, de trabalhar as diferenças, criando a partir disto novos caminhos epistêmicos e metodológicos como forma de compreender e enriquecer conhecimentos sobre as mais diversas áreas do saber (AZEVEDO; ANDRADE, 2007).

Esse subprojeto destacou-se, principalmente por proporcionar aos alunos bolsistas oportunidades de criação e participação em experiências metodológicas e práticas docentes de caráter inovador e interdisciplinar, o que se insere na perspectiva do projeto Capes. Também podemos afirmar que possibilitou, para além da interação dos bolsistas com os professores, o fortalecimento do trabalho em grupo, tendo o ensino voltado para a proposta pedagógica da escola, colaborando para o desenvolvimento de uma visão mais articulada com prática docente e a realidade da escola pública. 
Tendo em vista a complexidade do contexto escolar, nosso subprojeto buscou desenvolver atividades de inserção dos alunos na escola tendo como pressuposto metodológico a existência de pelo menos três dimensões interligadas na vida escolar (ANDRÉ, 1995): a dimensão institucional, a instrucional e a sociopolítico cultural.

A visão integrada dessas três dimensões a serem investigadas em diferentes momentos e pelos diversos participantes do subprojeto Pibid (alunos bolsistas e professores supervisores, professores colaboradores e professora coordenadora), foi construída coletivamente em reuniões, em atividades com a escola, envolvendo toda a equipe proponente, os professores supervisores e alunos bolsistas.

De maneira geral, os projetos desenvolvidos primaram pela interdisciplinaridade, em que foi possível o desenvolvimento de atividades que articulassem os conhecimentos específicos de cada área, ao mesmo tempo em que mobilizavam tanto a participação dos bolsistas dos diferentes cursos com os professores das várias disciplinas nas escolas e com os professores polivalentes. O entrosamento, o envolvimento e o planejamento de ações interdisciplinares contribuíram sobremaneira para a formação dos estudantes bolsistas, uma vez que esses foram mobilizados a pensar ações conjuntamente, discutindo e refletindo a respeito da importância da interdisciplinaridade como uma ponte para o melhor entendimento das disciplinas entre si e do trabalho docente.

Consideramos que essa parceria entre escola e universidade potencializou a participação dos professores em exercício na formação dos licenciandos, bem como fomentou a troca de saberes e experiências derivadas do campo do trabalho, assim como reafirmou as contribuições da universidade na formação continuada dos professores das escolas. Há de se destacar, também, que esse subprojeto conseguiu aproximar a formação universitária da realidade vivida pela escola pública em seu cotidiano. Acreditamos que o trabalho desenvolvido permitiu também uma melhor inserção do grupo junto à comunidade.

\section{DO PROFESSOR SUPERVISOR}

A professora supervisora foi inserida no projeto Pibid a partir de sondagem de seu interesse, pois já recebia, há algum tempo, alunos-pesquisadores em sua sala de aula, conhecendo um pouco da dinâmica desse trabalho parceiro.

Havendo interesse e curiosidade por parte da mesma, esta inscreveu-se no processo seletivo, foi selecionada e passou a fazer parte da equipe Pibid - edital 2011 - a partir de agosto de 2012 .

Todo trabalho que se mostra novo desperta dúvidas, e nesse caso não foi diferente. Na primeira reunião, que aconteceu na escola onde o Pibid iria ser desenvolvido, na qual estavam presentes educadores (da universidade e da referida escola) e alunos bolsistas de iniciação à docência que ali atuariam, a professora supervisora procurou expor algumas de suas dúvidas, obtendo algumas respostas:

No início da reunião levantei algumas dúvidas quanto às reuniões que deverei fazer com os alunos pesquisadores a cada 15 dias. Foi-me esclarecido que as reu- 
niões deverão durar 2 horas, que nesses momentos serão verificadas e assinadas as folhas de frequência dos alunos, que haverá o partilhar/trocas de experiências dos alunos pesquisadores na escola (...). Esses momentos também poderão ser usados para esclarecer dúvidas e/ou dificuldades, conversar sobre PPP, planejamento/conteúdos etc... (Professora Supervisora Bét - Registro 27/8/2012).

Aos poucos o lugar e o fazer da professora supervisora foram sendo entendidos e se constituindo, tanto para ela quanto para os alunos bolsistas de iniciação à docência.

A professora Bét fala sobre como está entendendo seu papel no Pibid (tudo tem se mostrado muito novo, para todos...) e como ela pode nos ajudar no processo de aproximação inicial e por todo o percurso do projeto, através de troca de telefones, e-mails, presença na escola, inclusive de manhã, caso se faça necessário (Bolsista Leandro - Registro 13/09/2012).

No fazer-se/constituir-se na condição de professora supervisora, ela se preocupou em delimitar/compreender as tarefas que tinha sob sua responsabilidade com os bolsistas e que enfatizavam o seu lugar de formadora dos futuros professores.

Entre as diferentes atividades a desenvolver com os alunos bolsistas de iniciação à docência, tinha a tarefa de supervisionar as atuações de seis alunos, de diferentes cursos: um aluno da Licenciatura de Educação Física, uma aluna da Licenciatura de Geografia, e quatro alunas da Licenciatura em Pedagogia. Lembrando que a proposta do subprojeto Pibid possuía caráter interdisciplinar. Também deveria acompanhar a inserção desses na escola, propondo estratégias de acolhimento no contexto escolar, e dando início ao desenvolvimento dos trabalhos em parceria, que iriam pensar e levar à prática com suas respectivas professoras colaboradoras.

A professora supervisora também era responsável por fazer reuniões na escola com todos os Pibidianos. De agosto a dezembro de 2012, as reuniões aconteciam a cada duas semanas, e no ano letivo de 2013, aconteceram a cada três semanas. Era estendido convite para essas reuniões, à equipe gestora da escola e aos professores orientadores da universidade, havendo, em algumas delas, a presença destes. Destacamos que a Professora Coordenadora da escola participava com regularidade, acompanhando os trabalhos em parceria, dando ideias e opiniões, ajudando, quando necessário, a criar pontes com a equipe gestora e com o grupo de professores; a professora tinha uma atitude comprometida com o subprojeto Pibid, acreditando no valor do mesmo tanto para a formação dos Pibidianos quanto para enriquecer o trabalho pedagógico da escola.

Todas as reuniões com os alunos bolsistas eram registradas por meio de texto escrito. O registro ficava, a cada encontro, sob a responsabilidade de um dos participantes.

A pauta dessas reuniões era definida pela professora supervisora, conforme necessidades que percebia em relação aos alunos bolsistas de iniciação à docência, em relação à escola, às parcerias, ao planejamento de atividades parceiras etc. A professora supervisora procurava incluir nessas pautas alguma leitura para fruição ou reflexão. Importante foi esta proposta para os bolsistas: 
Um ponto positivo das reuniões, dentre muitos, foi a iniciativa da professora supervisora trazer livros de literatura infantil para leitura ao final das reuniões. Mesmo sendo estudante de pedagogia, ainda não havia percebido o quão rico são os livros infantis e quantas possibilidades de discussões e trabalhos abrigam, e foi durante as reuniões que pude perceber tal contribuição (Bolsista Tatiana - Escrita acerca da professora supervisora Jan-2014).

A professora supervisora percebia que, a partir de textos/livros lidos, oportunidades de conversas/discussões poderiam surgir. Também entendia que a leitura, enquanto fruição/ deleite, poderia ser um recurso lúdico para aproximar os Pibidianos, tanto entre si quanto dela. Ainda, percebendo-se formadora dos futuros professores, e entendendo a importância da leitura no contexto escolar, objetivava despertar nos alunos bolsistas um "olhar atento" para a riqueza e importância da literatura no trabalho pedagógico.

Os Pibidianos se envolveram com essa prática e, algumas vezes, também fizeram/ partilharam suas leituras, oferecendo-se para tal ou a convite da professora supervisora.

Dani perguntou se podia ler um livro (...). Dani disse que, uma vez que conhecemos Bétsamar não ficamos mais iguais em relação à literatura, e que estava se encantando a cada dia. Bét leu a sinopse do livro "Acendedores de sonhos" e Dani disse que nós duas (Dani e Camila) estávamos com a ideia de apresentar a história na sala de informática para as duas turmas, com encenações e lanterna. Dani leu o livro para nós [...] (Bolsista Camila - Registro 22/08/2013).

Dani, a pedido de Bét, leu a poesia “Anão e gigante”, de Nilson José Machado, que a professora Tatiana $\left(3^{\circ}\right.$. ano) trabalhou com sua turma. [...] Bét fixou na lousa os painéis elaborados pela turma do $3^{\circ}$. ano com frases dos próprios alunos escrevendo as situações que os fazem sentir "anões" ou "gigantes" (Bolsista Gabriela - Registro 11/04/2013).

Nessas reuniões, os alunos bolsistas tinham possibilidade de socializar algumas situações conflitivas e problemas encontrados e, coletivamente, buscava-se solucioná-los. A solução estava nas mãos dos alunos bolsistas de iniciação à docência? Da professora supervisora? Da equipe? Da escola/Professora Coordenadora/Direção? Cabia à professora supervisora estar atenta às "pontes" que poderia fazer entre universidade-escola na busca por um trabalho melhor e produtivo, para todos, a cada dia.

Também era importante a professora supervisora ter um olhar atento a todos os acontecimentos narrados pelos bolsistas para, com sensibilidade, procurar compreender o quanto toda aquela vivência com a prática escolar estava repercutindo em seus processos formativos, em suas reflexões entre o que estudavam na universidade e vivenciavam na escola, na construção de experiências que poderiam usar no exercício da docência depois de formados. A professora supervisora os estimulava a fazerem "pontes" entre as vivências na universidade e na escola, observando o quanto essas experiências poderiam ser relevantes para a formação de cada um deles. 
Entender e partilhar a singularidade de cada parceria construída era importante para apurar o olhar dos bolsistas para as diferenças que se mostram nessas parcerias, bem como, entre cada sala de aula, entre cada grupo de alunos que as compõem, na maneira como cada professor conduz sua sala de aula. A professora supervisora entendia que apurar o olhar dos Pibidianos para esses acontecimentos poderia ajudá-los nas futuras escolhas enquanto docentes - o que vou fazer semelhante? O que vou fazer diferente? Por quê?

Enfim, a partir das falas dos alunos bolsistas a professora supervisora também via possibilidades de "pontes", ao enxergar quais necessidades e/ou satisfações dos mesmos seria importante partilhar com as professoras colaboradoras, com a Professora Coordenadora ou com a gestão, para suprir algo que precisassem ou partilhar sucessos nas parcerias estabelecidas.

Ao final do $1^{\circ}$. semestre de trabalho, a professora supervisora buscou, por meio de um momento avaliativo, perceber como foram aqueles primeiros meses de trabalho parceiro, bem como avaliar seu papel enquanto professora supervisora - o trabalho que buscava/ ajudava a desenvolver entre bolsistas, professores, equipe gestora, comunidade escolar e famílias, estava no "rumo" certo?

A professora supervisora orientou os bolsistas a, nessa avaliação, levantarem tanto pontos positivos quanto negativos em todos os aspectos do trabalho na escola: deles com a supervisora, deles entre eles, deles com seus professores parceiros, deles com a escola etc. A professora supervisora também iria fazer sua avaliação.

A partir do que fosse explanado nessas avaliações, a professora supervisora objetivava melhorar o trabalho parceiro a ser desenvolvido no ano seguinte.

Nessas avaliações, as reuniões feitas na escola apareceram, na maioria das falas/escritas, como sendo positivas. Elas foram percebidas como importantes momentos para expor opiniões, organizar o trabalho e buscar coletivamente a solução para dificuldades:

\footnotetext{
Organização das reuniões na escola, na quais tínhamos a oportunidade de expor nossas opiniões. Um ponto positivo foi a frequência com que ocorreram, facilitando a solução de problemas e organização de novas ações (Bolsista Tatiana - Avaliação dez./2012).
}

Os alunos bolsistas viram nas reuniões um "porto seguro" que lhes auxiliava quando precisavam, bem como, oportunizavam-lhes momentos de conversas, discussões e reflexões que os ajudavam a entender a dinâmica escolar:

Reuniões: Espaço diferenciado com uma dinâmica que consegue abranger todas as nossas necessidades, além de nos aproximar mais da escola e sua realidade (Bolsista Tatiana - Avaliação dez./2012).

O valor dessas reuniões confirmou-se no ano seguinte, quando, ao final de mais um ano letivo de parceria, novamente parou-se para avaliar o trabalho. 
Aprendi que reuniões são de extrema importância para organizar o trabalho e para ouvir o que acontece em outras salas, trocar experiências o que torna o trabalho mais rico (Bolsista Daniele - Avaliação dez./2013).

Quanto à organização do trabalho, a professora supervisora procurava estar atenta às possibilidades de trabalhos parceiros Pibid-escola, estimulando planejamentos e o efetivo desenvolvimento dos mesmos, e para tal, acompanhava as atividades dos alunos bolsistas de iniciação à docência com suas professoras parceiras e, toda vez que possível, os auxiliava na elaboração e desenvolvimento das atividades.

Também conversavam e definiam sobre planejamento de atividades conjuntas/coletivas, atividades essas que objetivavam ir além da parceria de cada aluno bolsista com sua professora parceira. Essas atividades envolviam vários e/ou todos os alunos bolsistas de iniciação à docência e diversas e/ou todas as salas de aulas.

Essas atividades conjuntas/coletivas eram propostas pela professora supervisora ou pelos bolsistas, a partir dos projetos pedagógicos da escola, como trânsito e meio ambiente. Também houve situações em que a Professora Coordenadora da escola procurou a professora supervisora para sugerir/averiguar possibilidade de trabalho parceiro que envolvesse toda a escola e todos os bolsistas.

Entre agosto de 2012 e dezembro de 2013, aconteceram três situações de atividades conjuntas/coletivas:

- Teatro de bonecos sobre trânsito, desenvolvido e apresentado por duas bolsistas, para todas as salas de aula do período da tarde, em setembro de 2012.

- História teatralizada, a partir do livro "O acendedor de sonhos", de Dorothée Piatek, sobre meio ambiente, apresentada por três bolsistas, para todas as salas de aula do período da manhã e da tarde, em setembro de 2013. A equipe gestora também assistiu a essa apresentação.

- Teatro de fantoches, envolvendo os temas trânsito e meio ambiente, desenvolvido e apresentado por todos os alunos bolsistas, para todas as salas do período da manhã e da tarde, em outubro de 2013. A equipe gestora e funcionários também assistiram a essa apresentação. A elaboração desse teatro proporcionou aos bolsistas vivenciarem um trabalho pedagógico interdisciplinar, no qual cada um pôde colaborar com o que trazia de sua formação.

Quanto à sua atuação diante da escola e dos educadores que estariam recebendo o projeto Pibid, e com isso, os alunos bolsistas de iniciação à docência, a professora supervisora deveria explicar, divulgar e tirar dúvidas sobre o trabalho do Pibid na escola. Procurava estar atenta à necessidade de retomar essas questões ao chegar novos professores ou novos alunos bolsistas de iniciação à docência na escola. Também deveria esclarecer que o aluno bolsista de iniciação à docência não era um estagiário, tendo um papel diferente deste na escola, com uma atuação mais ampla. Segue reflexão ocorrida em uma das reuniões na escola: 
Sinto que a escola, aos poucos, foi compreendendo a proposta do Pibid e nos reconhecendo como um grupo que gostaria de "somar forças" ao trabalho realizado (Bolsista Tatiana - Avaliação dez./2013).

Assim como a escola foi compreendendo a proposta do Pibid, também para os alunos bolsistas foi um aprendizado entender o sentido da presença deles no contexto escolar. Segundo Leandro:

[...] estamos na escola para aprender o que é ser professor, somos "alunos pesquisadores" porque pesquisamos o que é ser professor [...] (Bolsista Leandro - Registro 13/09/2012).

Ainda fazia parte da atuação da professora supervisora organizar e socializar com os alunos bolsistas de iniciação à docência os materiais enviados pela Coordenadora do subprojeto Pibid para a escola, cuidando da organização dos mesmos e da entrada e saída destes. Esses materiais eram usados em trabalhos parceiros desenvolvidos. A professora supervisora também deveria cuidar do saldo/cartão Xerox, controlando e conferindo entradas e saídas do mesmo.

A professora supervisora, com autorização da equipe gestora da escola, também procurava inserir os alunos bolsistas de iniciação à docência em situações cotidianas da escola, como: planejamento, reuniões de pais, HTPCs (Horário de Trabalho Pedagógico Coletivo), HTPIs (Horário de Trabalho Pedagógico Individual), atividades festivas, atividades pedagógicas extraescolares etc.

Para o planejamento, o convite era feito logo no início do ano letivo, momento em que o mesmo ocorre na escola.

Quanto às reuniões de pais, ela os avisava com antecedência da data da mesma, sugerindo que conversassem com os professores parceiros acerca da possibilidade de participarem delas, não apenas para que vivenciassem esse momento escola-família, mas também para que os pais os conhecessem pessoalmente e soubessem um pouco do trabalho parceiro desenvolvido. Segue colocação, de momento positivo, feita por uma aluna bolsista de iniciação à docência:

\footnotetext{
Abertura para participação na reunião de pais, momento muito importante para a escola e de grande aprendizado para minha formação (Bolsista Tatiana - Avaliação dez./2012).
}

Para que pudessem participar dos HTPCs, outro momento escolar importante para a formação dos futuros docentes, a professora supervisora organizava uma escala, distribuindo-os em duplas nos dias agendados para essas reuniões.

Quanto aos HTPIs, orientava não apenas os alunos bolsistas de iniciação à docência, mas também os professores parceiros que os recebiam, que procurassem, toda vez que necessário e possível, utilizar esses momentos para planejamento/organização das atividades 
parceiras. Conversava, com os professores da escola, a respeito da importância de, pelo menos uma vez ao mês, fazerem um HTPI com o aluno-bolsista que recebiam.

Para as atividades festivas e extraescolares, contava com o apoio da Professora Coordenadora da escola, que gentilmente avisava das datas e locais e estendia o convite ao grupo de alunos bolsistas de iniciação à docência.

Outra atuação da professora supervisora era com o mural de apresentação do Pibid e os painéis ações.

O mural de apresentação era montado com frase explicativa sobre o Pibid e fotos de todos os envolvidos com o trabalho parceiro, tanto da universidade quanto da escola. Por meio dele fazia-se uma apresentação inicial do trabalho parceiro para os pais, familiares e amigos dos alunos.

[...] E para que os pais não estranhassem nossa presença na escola de seus filhos ela [a professora supervisora] colocou nossas fotos com informativos sobre o Pibid na entrada da escola, o que nos aproximou de alguns deles (Bolsista Daniele - Produção escrita 15/12/2013).

Os painéis ações diziam respeito à exposição de cartazes com fotos legendadas de trabalhos parceiros que aconteciam. Possibilitavam a apresentação das "ações" que ocorriam a partir das parcerias bolsistas - professor colaborador e/ou de trabalhos coletivos envolvendo um ou mais bolsistas e várias ou todas as salas de aula da escola.

Os painéis ações eram montados e atualizados regularmente, pela professora supervisora e pelos alunos bolsistas de iniciação à docência, conforme as "ações" parceiras iam se concretizando.

O objetivo do mural de apresentação e dos painéis ações era informar, tanto à comunidade escolar quanto às famílias, o significado do Pibid, os envolvidos nessa parceria e o que de "concreto" estava acontecendo na escola e com os alunos a partir do trabalho parceiro universidade-escola.

Por meio deles, abria-se um canal de comunicação entre pais/familiares e os bolsistas, pois era comum os filhos mostrarem aos pais/familiares, nesses painéis, fotos de trabalhos que desenvolveram em atividades parceiras entre suas professoras e o Pibidiano que esta recebia.

A supervisora procurou dar destaque às ações que desenvolvíamos com os professores. Para isso ela criou o Painel Ações, que era colocado na parede de entrada da escola para que os pais visualizassem os trabalhos (Bolsista Daniele - Produção escrita 15/12/2013).

Por intermédio do mural de apresentações e dos painéis ações, os funcionários da escola também puderam inteirar-se da parceria universidade-escola e do significado da mesma.

Por fim, a professora supervisora procurava documentar todos os dados dos acontecimentos envolvendo o Pibid e seus trabalhos parceiros, como: pautas e registros das reuniões, fotos, avaliações, controle de materiais, recibos de Xerox, materiais confeccionados/ 
produzidos, mural de apresentação, painéis ações etc... Buscava manter essas informações organizadas para poderem ser resgatadas e usadas em qualquer situação/evento que se fizesse necessário.

Quando o Pibid - edital 2011 encerrou-se, a professora supervisora percebeu a importância de deixar para a escola esses dados, documentados e organizados, em um DVD. Também ficou para a escola cópias dos planejamentos elaborados pelos Pibidianos de suas atividades parceiras e uma pasta com fotos e textos de trabalhos desenvolvidos pelo grupo nesse período de parcerias. O objetivo para tal atitude foi oportunizar para a escola, e aos seus professores, material para futuras consultas pedagógicas.

Esse DVD, com cópias digitais dos planejamentos, fotos, textos etc., também foi partilhado com cada aluno bolsista de iniciação à docência, com as professoras orientadoras da universidade, com a professora coordenadora do Pibid - edital 2011 e com a Diretora do Departamento Pedagógico da Secretaria de Educação da cidade na qual está inserida a referida escola. A finalidade, nesse momento, foi tanto oferecer material para futuras consultas como partilhar a riqueza dessa experiência parceira com pessoas que foram significativas para que a mesma fosse possível.

Enfim, consideramos que a professora supervisora foi construindo, na relação com os bolsistas e com todos aqueles envolvidos com esse subprojeto, ações na dimensão formativa dos bolsistas, na dimensão administrativa, na dimensão afetiva e na dimensão das relações com a gestão escolar, com os professores parceiros, com os Pibidianos, com funcionários, com familiares, com a universidade...

O lugar da professora supervisora, no desenvolvimento dessa parceria universidade-escola, por meio do Pibid, mostrou-se importante desde os primeiros momentos. Momentos em que ainda eram dados os primeiros passos para que se constituísse o seu próprio lugar. Lugar que se revelou positivo devido aos frutos colhidos durante o tempo em que o Pibid atuou na escola. Frutos que apareceram na formação dos bolsistas, na formação dos professores colaboradores, nas agradáveis relações estabelecidas, no respeito das famílias pelos trabalhos desenvolvidos e, principalmente, no enriquecimento do trabalho pedagógico a partir da confiança do quão positivo podem ser as parcerias quando bem constituídas.

\section{Das falas dos alunos}

O subprojeto Pibid chegou ao seu fim em dezembro de 2013. No último encontro na escola, do qual participaram a professora supervisora, os bolsistas e uma das professoras orientadoras, foi feita avaliação acerca da importância do Pibid.

Foi um momento de fechamento do subprojeto Pibid muito rico, no qual os bolsistas falavam de seu processo de formação, da escolha pela docência...

Segue escrita sobre colocação de uma bolsista em registro elaborado pela supervisora:

[a bolsista Dani comentou que] a experiência com o Pibid a fez repensar a profissão e refletir sobre gestão, funcionários, relacionamentos com/na a escola; também comentou que o "estar" com a geografia abriu novos horizontes. [...] 
[a bolsista Dani comentou que] nesse momento de fechamento do projeto percebe-se com menos arrogância ao ver a escola; percebeu que esta faz parte da sociedade e não é fragmentada e o professor é um ser político; sente que amadureceu, principalmente ao olhar o outro, o pedagogo, com mais sensibilidade. Tem certeza que quer ser professora! (Professora Supervisora Bét - Registro $12 / 12 / 2013)$.

A professora orientadora que esteve presente nesse último encontro sentiu a necessidade de saber o que eles pensavam acerca do lugar da professora supervisora no contexto do Pibid. Assim, foi solicitado aos bolsistas uma escrita que deixasse em evidência qual o lugar da professora supervisora na vida deles, na sua formação. Tal solicitação ficou assim registrada em caderno da supervisora:

Lugar desta [supervisora] tanto na escola quanto nas reuniões feitas, pontuando no que favorece/ajuda, as dificuldades, dando sugestões e citando o papel da mesmo enquanto formadora, inclusive dando sugestões para as próximas reuniões (Professora Supervisora Bét - Registro 12/12/2013).

A seguir, socializamos algumas considerações elencadas pelos bolsistas e que dizem da importância da mesma.

Em relação à Professora Supervisora Bétsamar, posso dizer que esta fez um excelente trabalho, que por sinal foi de extrema importância para que nossas atividades fluíssem melhor dentro da escola. Ela conseguiu estabelecer bem essa ponte entre nós, a escola e a gestão, além de proporcionar um espaço riquíssimo para planejarmos nosso trabalho, trazer novidades, leituras, recados, etc. Sua cobrança e organização também mostrava o quão empenhada e comprometida estava conosco [...] (Bolsista Camila, janeiro de 2014).

[...] Primeiramente, ela nos abriu as portas da escola nos acolhendo e nos encaminhando para as professoras que aceitavam nossa presença em sala de aula, e quando a parceria não dava certo, a supervisora nos realocava em outra sala, além disso, ela pensava nas parcerias visando nos proporcionar experiências diferentes em séries e com professores que não tínhamos acompanhado ainda, ou seja ela estava sempre visando a nossa formação como professores.

[...] importante foram as reuniões que tínhamos com ela para discutir os projetos que estávamos realizando e os encaminhamentos que precisávamos fazer, além de distribuir as tarefas, pedir ajuda a ela quanto à relação com alguma professora, dar sugestões, ou para desabafar sobre alguma questão da escola.

A Bét nos ensinou que na escola antes de executarmos algum projeto devemos mostrar o que pretendemos fazer para a coordenadora, não como uma hierarquia, mas para que a direção esteja ciente do que está se passando, afinal de contas se alguma coisa der errado elas estariam a par do projeto, além de nos dar ideias para incrementar ou ajustar a proposta para determinada idade. [...]. Contudo podemos notar que o papel da supervisora na escola é muito importante e trabalhoso, mas quando é feito com competência (como foi feito pela 
professora Bétsamar), ele só tem a acrescentar tanto para a escola como para a formação dos alunos que passam por ela (Bolsista Dani, janeiro de 2014).

Sua função foi criar um maior vínculo entre os bolsistas e o corpo docente da escola, preocupação quanto nossa assiduidade dentro do projeto, cumprimento da carga horária dentro da escola, organização dos materiais utilizados, informação sobre projetos que a escola realizava, discussões ligadas às relações dos bolsistas e professores, orientações e trocas de experiências pedagógicas.

Me trouxe muita segurança nas práticas dentro do Dante, pois vi que ela estava realmente comprometida com nosso projeto desde o início, compactuando a confiança de todas as partes participantes do projeto.

Uma sugestão que acredito ser cabível neste momento é que possamos criar momentos onde a escola possa se aproximar da universidade. Isso poderia se dar em primeira instância pela vinda da supervisora em reuniões/outros dentro do departamento de educação. O objetivo disso é aproximar de fato as duas realidades, fazendo com que a universidade seja efetivamente pública, de todos. Reafirmando que a "verdade" não está dentro dos muros da universidade e sim, que esta universidade deve prestar seu serviço a população, a escola (Bolsista Bianca, janeiro de 2014).

No decorrer deste um ano e meio de projeto, o papel do professor supervisor foi ressiginificado. Primeiramente, porque de início somos levados a pensar que o papel cabível ao professor é somente a supervisão das atividades desenvolvidas na escola, afinal, esta é a denominação da função. E assim acreditei ser no início do projeto, enquanto ainda não nos conhecíamos. As primeiras reuniões, que serviram para compreender nosso papel dentro da escola, de certa forma, davam-nos esta impressão de que estávamos em uma reunião de supervisão: a tentativa de fazer as pontes entre direção/professores e nós, os assuntos burocráticos: o cartão Xerox e os saldos errados, os materiais, os recados...

Mas, com o passar do tempo e da frequência de reuniões, essas questões burocráticas e, obviamente, necessárias para o desenvolvimento do trabalho do Pibid na escola, deixaram de ocupar o centro das nossas reuniões para dar espaço a questões que surgiam. Recordo-me que iniciamos o trabalho em agosto de 2012, e em novembro a escola deveria celebrar o Dia da Consciência Negra. Foi neste momento que o Pibid foi convidado a trabalhar mais efetivamente com a escola. E creio também que foi a partir deste momento que nossas reuniões e, principalmente, a função da professora supervisora, começou a tomar outras características, trazendo mais a discussão essas possibilidades de trabalho. A partir deste trabalho a se realizar, as reuniões contaram com discussões de atividades que poderiam ser desenvolvidas, o que envolveu a partilha das práticas da professora supervisora conosco, bem como discussões apoiadas em textos e outras fontes. Assim, a partir deste trabalho, comecei a compreender a importância do papel deste professor dentro do Pibid, que não empreendia apenas a supervisão das nossas atividades ou a observância das questões burocráticas, mas que também tinha muito a contribuir com suas experiências.

[...] Não obstante, depois de encerrado mais um ano na escola, vejo que a grande contribuição da professora supervisora no decorrer do projeto foi dispor de 
sua prática para nossa formação, a sua busca em explicitar suas ações e as razões destas, na tentativa de nos auxiliar a compreender as dinâmicas da sala de aula e o fazer docente no cotidiano, em meio aos conflitos e as dificuldades que emergem. Percebi que seu trabalho foi, na escola, ser uma formadora, que sem a necessidade ou exigência de fundamentar suas ações em teorias não teve receios de expor seu modo de trabalhar e nos auxiliar com suas vivências. Compreendo que foi através dela que tivemos a oportunidade de entender melhor a dinâmica das relações que o professor estabelece com a gestão e com os outros professores; bem como o desenvolvimento dos projetos do grupo só foram possíveis através de suas mediações.

Sendo assim, o professor supervisor tem um importante e fundamental papel no desenvolvimento do projeto: além de contribuir para que as atividades planejadas ocorram, mediando as relações entre bolsistas e a escola; o supervisor também tem a oportunidade de contribuir para a formação dos bolsistas através de suas próprias experiências e práticas (Bolsista Tatiana, janeiro de 2014).

Pensamos que as considerações das bolsistas deixam com clareza o movimento promovido pela professora supervisora a partir do início do subprojeto Pibid na escola.

Da explicitação da necessidade de cuidar dos aspectos burocráticos como forma de melhor organizar o trabalho que seria realizado: "preocupação quanto nossa assiduidade dentro do projeto, cumprimento da carga horária dentro da escola, organização dos materiais utilizados" (Bianca), "os assuntos burocráticos: o cartão Xerox e os saldos errados, os materiais, os recados..." (Tati), "Sua cobrança e organização também mostrava o quão empenhada e comprometida" (Camila).

Dos vínculos estabelecidos, seja o acolhimento na inserção na escola como da confiança gerada promovendo "um maior vínculo entre os bolsistas e o corpo docente da escola" (Bianca).

Da importância da partilha, "as reuniões contaram com discussões de atividades que poderiam ser desenvolvidas, o que envolveu a partilha das práticas da professora supervisora conosco, bem como discussões apoiadas em textos e outras fontes" (Tati), "reuniões que tínhamos com ela para discutir os projetos que estávamos realizando e os encaminhamentos que precisávamos fazer, além de distribuir as tarefas, pedir ajuda a ela quanto à relação com alguma professora, dar sugestões, ou para desabafar sobre alguma questão da escola" (Dani).

Da importância de fazer pontes e articular o trabalho com as professoras parceiras e com a gestão da escola "a tentativa de fazer as pontes entre direção/professores" (Tati).

De comprometer a coordenação com os projetos que se fazem na escola responsabilizando também a eles pela implementação dos mesmos "devemos mostrar o que pretendemos fazer para a coordenadora" (Dani).

De revelar suas ações mostrando uma forma de ser professora "não teve receios de expor seu modo de trabalhar e nos auxiliar com suas vivências" (Tati).

De uma aposta que precisa de mais tempo para ser completamente efetivada "momentos onde a escola possa se aproximar da universidade. [...]. Reafirmando que a "verdade" 
não está dentro dos muros da universidade e sim, que esta universidade deve prestar seu serviço a população, a escola".

As considerações dos alunos abarcam questões burocráticas e administrativas que eles mesmos consideram necessárias para o funcionamento da proposta. Mas também dizem das relações necessárias com a equipe gestora e os outros professores para que o trabalho pudesse fluir. Ainda consideram como aspecto fundamental a relação que estabeleceram com a professora supervisora que, ao acolhê-los, assumiu o compromisso pela formação deles, abrindo-se, expondo-se, mostrando seu modo de ser professora, seu modo de fazer educação. Revelando nessa exposição a importância do compartilhamento dos saberes e levando os bolsistas a compartilharem suas próprias experiências, promovendo uma formação que está atenta ao diálogo e ao trabalho coletivo.

As considerações das bolsistas mostram a potencialidade do lugar da professora supervisora Bét no contexto do Pibid, evidenciando que a escola é sim um lugar de formação e de produção de saberes.

\section{DOS SABERES NECESSÁRIOS}

É nítido perceber a importância da intervenção da professora supervisora no processo formativo vivenciado junto aos bolsistas, universidade e com os seus próprios pares, exigindo da mesma inúmeros saberes de orientação educativa. A temática acerca dos saberes de orientação é um campo teórico-prático rico para estudos e análises na formação inicial e continuada de professores, pelo fato de que os saberes constituem-se elementos fundamentais na construção identitária desses profissionais que estão atuando na área e, também, para aqueles que estão em processo de formação inicial.

A conceituação que utilizamos ao apontarmos o papel dos saberes está ancorada em Azevedo (2009), que estuda a definição defendida por Tardif (2002) de que o saber docente é constituído de vários saberes específicos, que produzem a totalidade de ser professor na medida em que são oriundos de processos de aprendizagem e de formação. O corpo do saber docente é fruto das interconexões e características próprias do saber da profissão, saber das disciplinas, o saber curricular e o saber da experiência.

Nesse sentido, os saberes profissionais do professor são entrelaçados com os saberes provenientes da própria história de vida individual, da sociedade da qual faz parte, da história de vida desse professor enquanto aluno, das diferentes instituições formais e não formais com as quais esse professor teve contato e dos diferentes contextos e ambientes formativos. A trajetória pessoal e profissional percorrida pelo professor acaba contribuindo imensamente para a constituição de sua identidade, havendo dois grandes momentos na vida de cada professor que delimitam a constituição dessa identidade: a sua trajetória pré-profissional e a trajetória profissional.

O período destinado ao desenvolvimento profissional do professor no decorrer do exercício do seu ofício é também algo que precisa ser analisado e sobre o qual precisamos refletir. A construção da carreira do professor vai sendo tecida mediante as suas experiên- 
cias pré-profissionais que se entrecruzam ao próprio exercício de ser professor no dia a dia da sua profissão.

Há o estabelecimento de uma relação entre as aprendizagens que o professor realiza no seu ambiente de trabalho com o seu objeto de trabalho que é o aluno, tanto no âmbito individual como coletivo, mediante o desenvolvimento do processo de ensino e aprendizagem. Cunha (2006, p. 267) reforça que "dada essa condição, as relações que o professor estabelece com seu trabalho são de natureza humana, sujeitas a interferências valorativas e construídas num contexto de complexibilidade". Assim, nesse ambiente de trabalho do professor, os saberes são extremamente importantes e estão caracterizados como existenciais, sociais e pragmáticos.

Esses saberes estão sendo moldados no decorrer da própria história de vida dos professores e no desenrolar da ação profissional em que eles atuam como professores supervisores. Esses saberes são parte essencial do seu trabalho e se constituem como algo que dá sentido à carreira e indica, instiga e provoca um reolhar sobre essas mesmas ações.

Isto significa que esses saberes compõem o grande "campo" da ação dos professores supervisores no trabalho colaborativo que envolve a parceria universidade e escola por meio de uma ação tutoral frente aos bolsistas do Pibid, seus alunos da escola, equipe gestora e seus próprios pares, delimitando nesse processo estilos de cooperação.

Nessas, as ações tutorais dos professores supervisores podem vir a contemplar vários âmbitos: ações que potencializem as atividades profissionais; articulem os processos de ensino com a aprendizagem; estabeleçam atividades e práticas de prevenção educativa e para o desenvolvimento, e por fim ações que auxiliem os bolsistas Pibidianos para atuarem em contextos próprios ricos em diversidade educacional, social, econômica, cultural e étnica.

Ao se analisar as ideias centrais de Lázaro (1993), acerca do papel do professor supervisor no seu exercício tutorial, percebemos que se a ação de orientar o aluno está intimamente ligada aos processos de orientação para a vida e não só para determinado momento e ou conflito. Esses saberes acabam por se tornar condição necessária para que a confiança e a formação global do aluno se dê de forma mais profunda e não apenas no âmbito científico e técnico. Essas ações tutorais voltam-se, assim, mais para a orientação dos processos de ensino e aprendizagem dos bolsistas no exercício pré-profissional e em alguns momentos uma orientação que prima para o ensino acerca da diversidade cultural.

Destacamos que as ações tutorais da professora supervisora, neste estudo, acabam por estar focalizadas, em parte, para a prevenção educativa da ação proativa do bolsista no contexto educacional em que atua nas suas atividades dentro do projeto Pibid contando com os professores em serviço da escola parceira e com a equipe gestora para auxiliá-los com a formação desses futuros professores, reforçando a ideia de que o processo de orientar o aluno para a vida aponta a necessidade de acompanhá-lo sendo um professor supervisor que transmita confiança, respeito e discernimento, estando presente e sendo presença determinante nos processos de construção do senso de responsabilidade e autonomia.

Neste trabalho, podemos perceber que os caminhos dessas intervenções pelas mãos da professora supervisora acabaram por desenhar determinadas formas, maneiras, estilos 
de ser professora articulando o SER, do SABER FAZER e do SABER dessa profissional nas suas práticas cotidianas. Acreditamos que esse aspecto é fundamental nos processos de orientação, pois cada aluno é único, e as necessidades formativas deles devem ser respeitadas, valorizadas e principalmente trabalhadas. É importante que os professores supervisores compreendam que suas orientações podem gerar o avanço, a acomodação, o retraimento, o estancamento ou o crescimento do aluno nos processos de inserção no contexto real da sua prática docente.

Independente da forma de guiar os alunos nas diferentes fases e processos de formação nos exercícios pré-profissionais, Azevedo (2009) acredita que os professores supervisores precisam construir e reconstruir os saberes de orientação. Tendo clareza inclusive que as diferentes formas de tutorar os alunos não devam ser fechadas e únicas, mas precisam diferenciar-se mediante as necessidades que são observadas e sentidas nos alunos. Assim, a homogeneização e o enquadramento das ações dos professores supervisores devem ser evitados e como núcleo dessa ação a diversidade, a variabilidade e a profundidade nos encaminhamentos propostos aos alunos devem ser meta docente.

Glickman (1985) define a ação de supervisão como aquela que possa propiciar conexão entre o desenvolvimento individual e profissional, por meio de uma abordagem desenvolvimental da supervisão, que desencadeie nos bolsistas não apenas a capacidade de tomar decisões, como também, o desenvolvimento do pensamento abstrato. Portanto, o professor supervisor necessita compreender como o desenvolvimento humano vai sendo tecido, adaptando as suas intervenções frente às características, dificuldades e problemas dos licenciados. Glickman (1990) já apontava a importância desses aspectos no âmbito da supervisão, pois para ele a abordagem desenvolvimental da supervisão deve proporcionar a interação das necessidades individuais dos professores e o desenvolvimento profissional, conectado aos objetivos da própria escola. Assim, o objetivo da supervisão é aproximar e estabelecer o desenvolvimento individual, profissional e organizacional tanto dos atores que atuam na escola, quanto no desenvolvimento da escola enquanto instituição socioeducativa.

Essas ações tutorais caracterizadas por diferentes formas de intervenção do professor supervisor retratam, em sua grande maioria, a maneira de orientação que se utilizava na ação de tutorar seus alunos, possibilitando um novo olhar sobre essas ações em que seja necessário o desencadeamento dos saberes de orientação, para qualificar cada vez mais e melhor o trabalho formativo desses professores.

Ao olharmos como os professores supervisores desencadeiam a forma de intervenção junto aos bolsistas, é possível compreendermos que essas formas acabam por ditar estilos de fazer as intervenções perante esse grupo seleto de alunos que hoje dividem o espaço escolar durante seu processo formativo durante anos dentro da proposta do Pibid. Logo, os professores supervisores acabam tendo que desenvolver, também, estilos próprios de intervenção.

$\mathrm{Na}$ direção da organização de saberes de orientação dos professores supervisores, encontramos nos estudos de Azevedo e Andrade (2010) algumas possibilidades de correlação, pois é possível entendermos que os professores supervisores, ao assumirem a ação educa- 
tiva e formativa na escola junto à universidade precisam, também, aprender os saberes que os auxiliem ainda mais no exercício de ensinagem junto aos futuros professores, acolhendo e ensinando acerca da docência junto aos bolsistas do Pibid.

Os processos de supervisão desses professores que estão junto aos bolsistas Pibid devem permear tanto o espaço formativo da escola como da universidade, exigindo desses professores saberes profissionais tais como:

1. Ação colaborativa dos diferentes profissionais da escola: articulação de pessoas e propostas formativas num clima de cooperação e trabalho coletivo.

2. Ressignificação da própria experiência como docente: redimensionamento do trabalho docente desenvolvido mediatizado pela capacidade crítico-reflexiva de intervenção profissional.

3. Articulação entre os espaços formativos da escola e da universidade: coabitar os diferentes espaços transformando em lugares de formação e autoformação de si e dos sujeitos que atuam na coletividade.

Ao analisarmos o processo vivido pela supervisora, foco deste estudo, junto aos alunos bolsistas e aos professores da universidade podemos afirmar que nesse processo os saberes aqui apresentados acabam por se constituir fundamentais, pois como envolvem uma trama de conhecimentos, habilidades e atitudes os saberes agora de orientação coadunam com os saberes docentes e são, também, como coloca Tardif (2002), temporais, plurais, heterogêneos, personalizados e situacionais, porque são apropriados, incorporados e subjetivados por meio das experiências profissionais da professora supervisora com os diferentes atores em inúmeras e diversificadas situações de trabalho coletivo.

Assim, podemos afirmar que o ato profissional de um professor supervisor deva ser estendido e entendido não só junto aos bolsistas e professores da universidade parceira, mas, também, junto aos outros alunos, com seus pares e com as próprias instituições formadoras (escolas e universidades). Essa ação de supervisão exige, então, que o professor seja capaz de realizar uma série de atividades que determinarão o sistemático desenvolvimento de saberes que precisam ser incorporados no dia a dia do seu trabalho docente.

Segundo Azevedo e Andrade (2010), o professor supervisor/tutor deve possuir três qualidades distintas não excludentes: qualidades humanizadoras, científicas e técnicas. Essas dimensões visam dar conta de um profissional que não só desenvolve uma ação tutoral, mas que, a partir disso, realmente propicie a formação integral dos seus alunos, e dos próprios professores universitários auxiliando inclusive nos processos de formação inicial.

\section{CONSIDERAÇões FINAIS}

Neste trabalho, tivemos a pretensão de analisar quais os saberes mobilizados por uma professora supervisora Pibid. O trabalho realizado com os bolsistas mostra a variedade de ações que são promovidas para aqueles que possam desenvolver saberes necessários à prática docente, à ação docente comprometida com os alunos e com a educação. 
O desenvolvimento deste trabalho legitima que a escola é um lugar de formação e de produção de saberes. Um espaço no qual tanto bolsistas como professora supervisora entraram em um processo de formação. Um espaço no qual tiveram que assumir responsabilidades e desenvolver ações com os alunos. Um espaço no qual foi possível viver as contradições, limites e possibilidades da escola. Um espaço que ganhou vida ao ser experienciado. Viver a escola e aprender nela ganham outros sentidos quando os bolsistas estiveram implicados na parceria com professores e alunos. Um espaço no qual a professora supervisora também, ao viver a escola e aprender nela, desenvolve ações desconhecidas até então. Como articular? Como fazer pontes? Como integrar ações? Talvez as ações que uma professora supervisora desenvolve no contexto do Pibid ofereçam pistas para pensar na promoção do trabalho coletivo na escola e ao mesmo tempo também auxiliem os próprios professores universitários nas suas práticas docentes, redimensionando-as na medida em que entendem o verdadeiro significado de articular a teoria com a prática real, contextual e situacional. Isto ainda fica mais evidente ao dizer dos saberes necessários, já elencados neste trabalho e que reiteramos aqui:

1. Ação colaborativa dos diferentes profissionais da escola: articulação de pessoas e propostas formativas num clima de cooperação e trabalho coletivo. E acrescentamos, legitimando que o trabalho no contexto escolar precisa de ações coletivas, as dificuldades enfrentadas são de todos e por isso a resolução das mesmas teria que ser responsabilidade conjunta. Há ainda um longo caminho a ser percorrido nessa direção, haja vista inclusive o fato de que a cultura universitária ainda impera muito fortemente uma prática profissional individualista, que dificulta as ações colaborativas entre os próprios professores universitários, aligeirando ações colaborativas extramuros.

2. Ressignificação da própria experiência como docente: redimensionamento do trabalho docente desenvolvido mediatizado pela capacidade crítico-reflexiva de intervenção profissional. E acrescentamos, refletindo sobre sua potencialidade para pensar nessa reflexão sua ação com os outros. Nesse saber, apontamos o desafio do professor tutor desencadear uma atitude docente e tutoral de ação reflexiva sobre si mesmo e sobre os outros, de forma a potencializar avanços nas práticas, avançando significativamente no autodesenvolvimento profissional.

3. Articulação entre os espaços formativos da escola e da universidade: coabitar os diferentes espaços, transformando em lugares de formação e autoformação de si e dos sujeitos que atuam na coletividade. E acrescentamos, outra articulação, uma parceria que se constrói no respeito e compromisso mútuo pela formação: formação dos alunos da escola, formação dos bolsistas (futuros professores), formação de professores da escola e da universidade, que percebem que a educação tem a intencionalidade de emancipar os sujeitos, e que essa tarefa não é fácil, e que precisa do compromisso tanto da escola como da universidade. 


\section{REFERÊNCIAS}

ANDRÉ, Marli. Etnografia da prática escolar, SP: Papirus, 1995.

AZEVEDO, Maria Antonia Ramos de; ANDRADE, Maria F. de. Os professores formadores e os saberes de orientação mediante ações tutorais. Educação, Porto Alegre, v. 33, n. 3, p. 213-221, set./dez., 2010.

AZEVEDO, Maria Antonia Ramos de. Os Saberes de Orientação dos Professores Formadores: desafios para Ações Tutorais Emancipatórias. Tese de Doutorado, São Paulo, Faculdade de Educação/USP, 2009.

BRASIL. Decreto nº. 7.219, de 24/06/2010 - Dispõe sobre o Pibid. Diário Oficial da União. $\mathrm{N}^{\mathrm{o}}$. 120, sexta-feira, 25 de junho de 2010. Disponível em: <http://www.capes.gov. br/images/stories/download/legislacao/Decreto7219_Pibid_240610.pdf>.

BRASIL. Novo Regulamento do Pibid - Portaria Capes, nº. 96, de 18 de julho de 2013. Disponível em: <http://www.capes.gov.br/educacao-basica/capesPibid/documentos-Pibid $>$.

BRASIL. Ministério da Educação - MEC, Secretaria de Educação Básica. Orientações curriculares para o Ensino Médio: Ciências da natureza, matemática e suas tecnologias, Brasília, 2006.

BRASIL. Resolução CNE/CP nº 1, de 18 de fevereiro de 2002. Institui Diretrizes Curriculares Nacionais para a Formação de Professores da Educação Básica, em nível superior, curso de licenciatura, de graduação plena, Brasília: MEC/CNE, 2002. Disponível em: <http://portal.mec.gov.br/cne/arquivos/pdf/rcp01_02.pdf>.

CUNHA, Maria Isabel. Docência na Universidade, Cultura e Avaliação Institucional: Saberes Silenciados em Questão. Revista Brasileira de Educação, Rio de Janeiro, 2006; 11 (32) p. 83-96.

FAZENDA, I. A interdisciplinaridade: um projeto em parceria, SP: Loyola, 1993.

GATTI, Bernardete A.; ANDRÉ, Marli, E. D. A.; GIMENES, Nelson A. S.; FERRAGUT, Laurizete. Um estudo avaliativo do Programa Institucional de Bolsa de Iniciação à Docência (Pibid), São Paulo: FCC/SEP, 2014.

GLICKMAN, Carl David. By YTM. Supervision. In: HOUSTON, WR. Handbook of Research on teacher education, Nova Iorque: McMillan Publishing Company; 1990; p. 549-566.

GLICKMAN, Carl David. Supervision of Instruction. A Developmental Approach, Boston: Allyn and Bacon, 1985.

LÁZARO, Angel Martinez; ASENSI, Jésus. Manual de Orientación Escolar y Tutoria, Madrid: Narcea, 1993. 
SANCHEZ, Serafín. La Tutoria dos los Centros Docentes: Manual de Profesor Tutor, Madrid: Escuela Española, 1993.

TARDIF, Maurice. Saberes docentes e formação profissional, Petrópolis, RJ: Vozes, 2002.

\section{Dados das Autoras}

\section{Laura Noemi Chaluh}

Doutora em Educação pela Universidade Estadual de Campinas. Professora do Departamento de Educação e do Programa de Pós-Graduação em Educação da Universidade Estadual Paulista. Rio Claro/SP - Brasil. lchaluh@rc.unesp.br

\section{Bétsamar Scopinho Martins}

Licenciatura em Pedagogia pela Universidade Estadual Paulista. Especialização: Pós-graduação "Psicopedagogia no Processo Ensino-Aprendizagem" (Faculdades Claretianas). Professora da Secretaria Municipal de Rio Claro e Professora Supervisora Pibid. Rio Claro/SP - Brasil. di_bet@hotmail.com

\section{Maria Antonia Ramos De Azevedo}

Doutora em Educação pela Universidade de São Paulo. Professora Assistente Doutora II na Universidade Estadual Paulista. Rio Claro/SP - Brasil. razevedo@rc.unesp.br

\section{Andreia Osti}

Doutora em Educação pela Faculdade de Educação da Universidade Estadual de Campinas. Professora do Departamento de Educação da Universidade Estadual Paulista e credenciada junto ao Programa de Pós-Graduação em Educação. Rio Claro/SP - Brasil. aosti@rc.unesp.br

Submetido em: 25-7-2015

Aceito em: 14-2-2017 